\title{
FONTES E MODOS DE APLICAÇÃO DE FÓSFORO PARA O MILHO EM SOLO CULTIVADO DA REGIÃO DO CERRADO ${ }^{(1)}$
}

\author{
Alvaro Vilela de Resende ${ }^{(2)}$, Antonio Eduardo Furtini Neto ${ }^{(3)}$, Vera \\ Maria Carvalho Alves ${ }^{(4)}$, Joel Augusto Muniz ${ }^{(5)}$, Nilton Curi ${ }^{(3)}$, \\ Valdemar Faquin $^{(3)}$, Daniel Ioshiteru Kimpara ${ }^{(2)}$, José Zilton \\ Lopes Santos $^{(6)}$ \& Leandro Flávio Carneiro ${ }^{(6)}$
}

\begin{abstract}
RESUMO
O uso eficiente de fertilizantes fosfatados nos solos da região tropical ainda constitui um desafio, principalmente considerando o manejo de longo prazo. Com base nas respostas acumuladas de três cultivos sucessivos de milho, compararamse alternativas de fornecimento de $P$, combinando fontes e modos de aplicação, num Argissolo Vermelho adubado em épocas passadas. O delineamento experimental foi o de blocos casualizados com quatro repetições, num esquema fatorial 4 × $3+1$, envolvendo quatro fontes de $\mathrm{P}$, na dose de $180 \mathrm{~kg} \mathrm{ha}^{-1}$ de $_{2} \mathrm{P}_{2} \mathrm{O}_{5}$ (superfosfato triplo-ST, termofosfato magnesiano Yoorin - TM, fosfato reativo de Arad - FR e fosfato natural de Araxá - FA), três formas de aplicação (a lanço em área total no primeiro ano, localizada no sulco de plantio no primeiro ano e parcelada anualmente no sulco) e uma testemunha (sem aplicação de $\mathrm{P}$ ), como tratamento adicional. $\mathrm{O} P$ foi fornecido, considerando os teores totais do nutriente nas fontes. Ao final dos três cultivos de milho, foram totalizados a produção de biomassa e de grãos e o acúmulo de $P$ na parte aérea e nos grãos. Determinaram-se os teores de $P$ residual no solo ao final do experimento. Foram calculados índices de eficiência agronômica e econômica. Foram detectadas mais diferenças em termos de absorção
\end{abstract}

\footnotetext{
(1) Parte da Tese de Doutorado do primeiro autor, apresentada ao Departamento de Ciência do Solo da Universidade Federal de Lavras - UFLA. Projeto financiado pelo CNPq. Recebido para publicação em agosto de 2004 e aprovado em março de 2006.

(2) Pesquisador da Embrapa Cerrados. Rodovia BR 020, Km 18, Caixa Postal 08223, CEP 73310-970 Planaltina (DF). E-mails: alvaro@cpac.embrapa.br, kinpara@cpac.embrapa.br

(3) Professor do Departamento de Ciência do Solo, Universidade Federal de Lavras - UFLA. Caixa Postal 3037, CEP 37200-000 Lavras (MG). Bolsista do CNPq. E-mails: afurtini@ufla.br; niltcuri@ufla.br; vafaquin@ufla.br

(4) Pesquisadora da Embrapa Milho e Sorgo. Caixa Postal 151, CEP 35701-970 Sete Lagoas (MG). E-mail: vera@cnpms.embrapa.br

(5) Professor do Departamento de Ciências Exatas, UFLA. Bolsista do CNPq. E-mail: joamuniz@ufla.br

(6) Pós-Graduando do Departamento de Ciência do Solo, UFLA. E-mail: santosilton@yahoo.com.br, leoflacar@yahoo.com.br
} 
de $\mathbf{P}$ do que de produtividade de grãos. A maioria dos tratamentos proporcionou incrementos de produção semelhantes, o que, em parte, foi atribuído ao residual de adubações passadas e à eficiência genotípica do milho a $P$. As fontes mais solúveis, ST e TM, apresentaram desempenho similar. Para o FR, maior produção foi obtida com a aplicação parcelada no sulco, o que não se verificou no caso do FA. $O$ parcelamento da dose total das fontes em aplicações anuais no sulco não comprometeu a produtividade do milho e propiciou maior efeito residual. Os tratamentos com maior eficiência agronômica (ST e TM) não corresponderam aos de maior eficiência econômica. Os dois fosfatos naturais (FR e FA) apresentaram relação benefício/custo mais compensadora.

Termos de indexação: adubação fosfatada, eficiência de fosfatos, fosfato natural, fosfato reativo, termofosfato, Zea mays $\mathrm{L}$.

\section{SUMMARY: PHOSPHORUS SOURCES AND APPLICATION METHODS FOR MAIZE IN SOIL OF THE CERRADO REGION}

The efficient use of phosphate fertilizers in soils of the tropical region is still a challenge, mainly regarding long-term soil management. Based on the cumulative response of three successive maize cultivations, alternatives of phosphorus supply combining $P$ sources and application methods were compared in a formerly fertilized Red Argisol. Treatments arranged in a $4 x 3+1$ factorial scheme represented by four $\mathrm{P}$ sources $\left(180 \mathrm{~kg} \mathrm{ha} \mathrm{H}^{-1} \mathrm{P}_{2} \mathrm{O}_{5}\right)$ as triple superphosphate - TS, magnesium termophosphate - MT, Arad reactive rock phosphate - RP, and Araxá rock phosphate - AP, and three application methods (broadcasted in the first year; along the sowing furrow in the first year; and annually split along the sowing furrow) and a check plot (without Papplication) as additional treatment. The applied P ratio was based on the total $\mathrm{P}_{2} \mathrm{O}_{5}$ content of each fertilizer. Cumulative biomass production, grain yield, and $P$ accumulation in shoot and grain were determined. Residual available soil P was quantified at the end of the experiment. Indices of agronomic and economic efficiency were calculated. More differences between treatments were detected in P uptake than in grain yield. Most treatments provided similar yield increments, which was partly attributed to the residual effect of previous fertilizations and the genetic efficiency of P use by the corn plants. The most soluble sources, TS and MT, presented comparable performances. Unlike the AP rock phosphate, the split application of RP in the sowing furrow led to higher yields. Annual split applications along the sowing furrow did not affect the grain yield, and increased the residual effect. The treatments with greatest agronomic efficiency (TS and MT) were not the same as those with greatest economic efficiency. The two rock phosphates (RP and AP) presented the most favorable cost/benefit ratios.

Index terms: phosphate fertilization, phosphate efficiency, rock phosphate, reactive rock phosphate, thermophosphate, Zea mays $L$.

\section{INTRODUÇÃO}

A produção em larga escala de milho e de outros grãos no Cerrado somente tornou-se viável com o desenvolvimento de tecnologias de melhoria da fertilidade dos solos da região. O requerimento de grandes quantidades de fosfatos na correção da fertilidade desses solos e a ausência de reservas abundantes de rochas fosfatadas de boa qualidade no País, associados ao elevado custo dos fertilizantes, justificam estudos para otimizar a eficiência no uso de adubos fosfatados. De um lado, têm-se variações quanto à natureza e à solubilidade de fosfatos naturais e industrializados e, de outro, a interação com os componentes edáficos, que inluenciam fortemente a disponibilização do $\mathrm{P}$ às plantas (Horowitz \& Meurer, 2003; Prochnow et al., 2003). Além disso, a forma de utilização dos fertilizantes, as características da planta cultivada e as condições climáticas exercem papel regulador das respostas em produção (Goedert et al., 1986; Coelho \& Alves, 2003; Sousa \& Lobato, 2003).

Os fosfatos solúveis, ao disponibilizarem prontamente o $\mathrm{P}$, têm apresentado bons resultados em diferentes formas de aplicação. Os fosfatos naturais apresentam, normalmente, menor eficiência, em especial no ano da aplicação e nas culturas anuais, as quais apresentam alta demanda de $\mathrm{P}$ num curto 
espaço de tempo (Goedert \& Lobato, 1984; Goedert et al., 1986; Goedert \& Lopes, 1987; Raij, 1991; Sousa \& Lobato, 2003). Tem-se evidenciado, também, a existência de diferenças entre os fosfatos naturais importados (fosfatos reativos, de origem sedimentar) e os nacionais (fosfatos de baixa reatividade, de origem ígnea ou metamórfica) quanto ao potencial de suprimento de P. Os fosfatos reativos parecem bastante promissores para uso direto na adubação em diversas combinações de culturas e sistemas de manejo do solo (Kaminski \& Peruzzo, 1997; Horowitz \& Meurer, 2003; Sousa \& Lobato, 2003). Contudo, não é simples a predição das respostas à adubação. Ao considerar a produção acumulada de vários cultivos após a aplicação, verifica-se que o desempenho de alguns fosfatos naturais pode equiparar-se ao das fontes mais solúveis. Isso se explica pelo fato de o $\mathrm{P}$ prontamente liberado dos fertilizantes solúveis passar para formas menos disponíveis, enquanto os fosfatos naturais vão sendo solubilizados no decorrer do tempo (Novais \& Smyth, 1999).

Para o milho, em sistemas mais tecnificados, os gastos com correção do solo e adubação representam, em média, 40 a $45 \%$ do custo de produção (Coelho \& Alves, 2003). Os gastos com a adubação fosfatada representam parte considerável do custo das lavouras na região do Cerrado e variam, dependendo da fonte de $\mathrm{P}$ utilizada e do prazo considerado para o retorno do investimento (Sousa et al., 2002). O manejo da fertilidade do solo em relação ao $\mathrm{P}$ deve ser planejado numa perspectiva de longo prazo, uma vez que o custo da adubação e as respostas em produtividade estão sujeitos a muitas incertezas e podem variar de um ano para outro (Fixen \& Halvorson, 1991; Reetz Junior \& Fixen, 1992; Sousa \& Lobato, 2003). Um aspecto importante é que a relação benefício/custo do uso de fosfatos pode diferir muito, quando se considera a produção obtida no ano da aplicação ou a produção acumulada de vários cultivos.

Tendo em vista que uma fração relativamente pequena do $\mathrm{P}$ é aproveitada no primeiro ano, enquanto o restante permanece no solo, em formas de maior ou menor disponibilidade às plantas, o efeito residual passa a ser um componente muito importante na avaliação agronômica e econômica de práticas de adubação fosfatada. São escassos os experimentos de campo de longa duração, sem os quais não é possível considerar satisfatoriamente o efeito residual (Barbosa Filho, 1984; Goedert \& Lobato, 1984; Sousa \& Lobato, 2003). Da mesma forma, poucos são os trabalhos dessa natureza realizados em áreas que já receberam adubações anteriores e em sistemas de produção com menor revolvimento do solo.

Objetivou-se comparar a eficiência agronômica e econômica de fontes e modos de aplicação de $\mathrm{P}$ em solo da região do Cerrado, adubado anteriormente, considerando as respostas cumulativas obtidas após três cultivos sucessivos de milho.

\section{MATERIAL E MÉTODOS}

O estudo foi realizado na Fazenda Boa Vista, município de Itumirim, MG, situado a $21^{\circ} 19^{\prime} 02$ " de latitude sul e $44^{\circ} 52$ ' 14 " de longitude oeste, a uma altitude média de $871 \mathrm{~m}$. A área experimental apresenta Argissolo Vermelho distrófico típico textura argilosa. O local foi anteriormente cultivado e adubado e, há cerca de dez anos, não era utilizado para lavouras, permanecendo coberto por vegetação espontânea dominada por capim-braquiária (Brachiaria brizantha) e servindo ao pastejo bovino. Quanto às condições de fertilidade do solo, antes da instalação do experimento, salienta-se a baixa disponibilidade de $\mathrm{P}$ pelos extratores Mehlich-1 (Alvarez V. et al., 1999) e resina de troca iônica (Raij et al., 1996) (Quadro 1).

Foram efetuados três cultivos consecutivos de milho em condições de sequeiro, nos anos agrícolas 2000/2001, 2001/2002 e 2002/2003, utilizando-se híbridos triplos desenvolvidos pela Embrapa Milho e Sorgo (HT 9710-11, HT 7105-3 e BRS 3003, respectivamente). As parcelas corresponderam a cinco linhas de milho com $6 \mathrm{~m}$ de comprimento e $0,9 \mathrm{~m}$ espaçadas entre si $\left(27 \mathrm{~m}^{2}\right)$. Nas avaliações do experimento, foi considerada uma área útil central de 10,8 $\mathrm{m}^{2}$ (três linhas de $4 \mathrm{~m}$ de comprimento).

O estudo consistiu da avaliação da resposta do milho ao fornecimento de $180 \mathrm{~kg} \mathrm{ha}^{-1} \mathrm{de}_{2} \mathrm{O}_{5}$, testando-se quatro fosfatos (ST - superfosfato triplo, TM termofosfato magnesiano Yoorin, $\mathrm{FR}$ - fosfato reativo de Arad, e FA - fosfato natural de Araxá) e três modos de aplicação (a lanço em área total no primeiro ano, aplicada no sulco de plantio no primeiro ano e parcelada no sulco em três anos). No terceiro modo de aplicação, a dose total de $180 \mathrm{~kg} \mathrm{ha}^{-1}$ de $\mathrm{P}_{2} \mathrm{O}_{5}$ foi dividida em aplicações anuais no sulco de semeadura, fornecendose, portanto, $60 \mathrm{~kg} \mathrm{ha}^{-1}$ de $\mathrm{P}_{2} \mathrm{O}_{5}$ a cada cultivo. $\mathrm{O}$ experimento foi instalado em delineamento de blocos casualizados, com quatro repetições, num arranjo fatorial $4 \times 3+1$, combinando as quatro fontes de $\mathrm{P} \mathrm{e}$ as três formas de aplicação, mais uma testemunha sem fornecimento de $\mathrm{P}$ (tratamento adicional).

A quantidade aplicada de cada fonte foi calculada com base no teor de $\mathrm{P}_{2} \mathrm{O}_{5}$ total dos fertilizantes (Quadro 2). Na aplicação a lanço, os fertilizantes foram distribuídos manualmente em toda a área da parcela experimental e incorporados, com enxada, a cerca de $10 \mathrm{~cm}$ de profundidade. Nas aplicações localizadas, os fertilizantes foram distribuídos no fundo do sulco de semeadura.

No primeiro ano, antes do preparo do solo, a área recebeu calcário dolomítico em dosagem determinada pelo método da curva de incubação em laboratório $\left(1,5 \mathrm{t} \mathrm{ha}^{-1}, \mathrm{PRNT}=100 \%\right)$, visando obter valores de $\mathrm{pH}$ próximos de 5,5. O preparo do solo foi feito com aração e gradagens. Cerca de 40 dias após a calagem, foram abertos os sulcos de semeadura, sendo aplicados 
os tratamentos em seguida. O preparo do solo foi realizado apenas na primeira safra. Após cada colheita, os restos culturais (parte aérea do milho) foram removidos das parcelas, deixando-se o solo em pousio. Para o segundo e o terceiro cultivo, os sulcos de semeadura foram abertos com enxada, seguindo sua localização original. As parcelas referentes aos tratamentos com adubação fosfatada parcelada receberam os fosfatos concomitantemente à adubação de base.
A definição das quantidades de nutrientes foi feita, tomando-se, como referência, as recomendações de adubação de Minas Gerais, para expectativas de produtividade acima de $8 \mathrm{t} \mathrm{ha}^{-1}$ de grãos (Alves et al., 1999) (Quadro 3). Foram distribuídas cerca de dez sementes de milho por metro de sulco, com posterior desbaste, deixando-se cinco plantas por metro. As adubações de cobertura foram iniciadas a partir do estádio de seis a oito folhas, e os fertilizantes aplicados em filete ao lado da linha de plantas. Procedimentos

Quadro 1. Principais atributos químicos e físicos do solo (0-20 cm de profundidade) antes da aplicação dos tratamentos

\begin{tabular}{|c|c|c|c|c|c|c|c|c|c|c|c|c|}
\hline \multirow{2}{*}{$\mathrm{pH} \mathrm{H}_{2} \mathrm{O}$} & \multicolumn{3}{|c|}{$\mathbf{P}$} & \multirow{2}{*}{$\mathbf{K}^{+}$} & \multirow{2}{*}{$\mathrm{Ca}^{2+}$} & \multirow{2}{*}{$\mathrm{Mg}^{2+}$} & \multirow{2}{*}{$\mathrm{Al}^{3+}$} & \multirow{2}{*}{$\mathrm{H}+\mathrm{Al}$} & \multirow{2}{*}{ MO } & \multirow{2}{*}{ Areia } & \multirow{2}{*}{ Silte } & \multirow{2}{*}{ Argila } \\
\hline & Remanescente & Mehlich-1 & Resina & & & & & & & & & \\
\hline
\end{tabular}

\begin{tabular}{|c|c|c|c|c|c|c|c|c|c|c|c|c|}
\hline \multirow[b]{2}{*}{5,2} & \multirow{2}{*}{$\begin{array}{c}\mathrm{mg} \mathrm{L}^{-1} \\
16,8\end{array}$} & \multicolumn{3}{|c|}{$\mathrm{mg} \mathrm{dm}^{-3}$} & \multicolumn{4}{|c|}{$\mathrm{cmol}_{\mathrm{c}} \mathrm{dm}^{-3}$} & \multicolumn{4}{|c|}{$\mathrm{g} \mathrm{kg}^{-1}$} \\
\hline & & 2,0 & 7,8 & 34,0 & 1,2 & 0,3 & 0,5 & 5,0 & 37 & 360 & 100 & 540 \\
\hline
\end{tabular}

Quadro 2. Caracterização química e física dos fertilizantes fosfatados

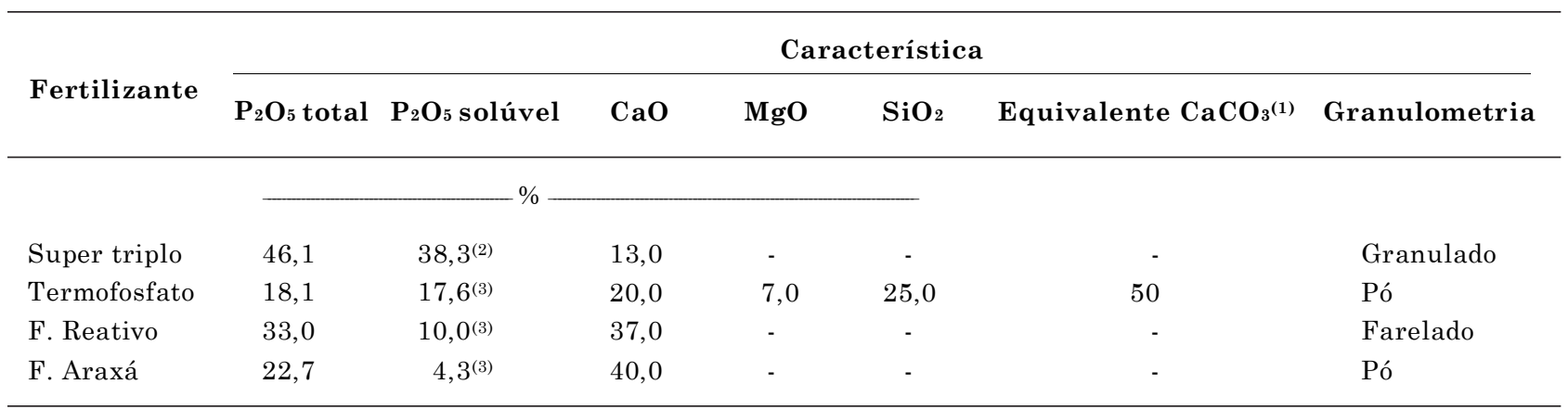

(1) Efeito alcalinizante dado em $\mathrm{kg} \mathrm{CaCO}_{3}$ para cada $100 \mathrm{~kg}$ do fertilizante. ${ }^{(2)} \mathrm{e}^{(3)} \mathrm{P}_{2} \mathrm{O}_{5}$ solúvel em água e em ácido cítrico a $2 \%$ (1:100), respectivamente. Análises realizadas no Laboratório de Química da Esalq/USP, Piracicaba-SP.

Quadro 3. Datas de semeadura e adubações dos três cultivos de milho

\begin{tabular}{|c|c|c|c|c|c|c|c|c|}
\hline \multirow{2}{*}{ Ano agrícola } & \multirow{2}{*}{ Data de semeadura } & \multicolumn{5}{|c|}{ Adubação de semeadura } & \multicolumn{2}{|c|}{ Adubação de cobertura } \\
\hline & & $\mathbf{N}$ & $\mathbf{K}_{2} \mathbf{O}$ & $\mathbf{S}$ & $\mathbf{B}$ & $\mathrm{Zn}$ & $\mathbf{N}$ & $\mathbf{K}_{2} \mathbf{O}$ \\
\hline & & \multicolumn{7}{|c|}{ - $\mathrm{kg} \mathrm{ha}^{-1}$} \\
\hline $2000 / 01$ & $25 / 11 / 00$ & $21^{(1)}$ & $90^{(2)}$ & $24^{(\mathbf{1})(3)}$ & - & $2,0^{(3)}$ & $56^{(4)} \times 3$ & $3^{(4)} \times 3$ \\
\hline $2001 / 02$ & $20 / 11 / 01$ & $21^{(1)}$ & $90^{(2)}$ & $24^{(\mathbf{1})(3)}$ & - & $2,0^{(3)}$ & $78^{(4)} \times 2$ & $4^{(4)} \times 2$ \\
\hline $2002 / 03$ & 09/11/02 & $73^{(\mathbf{5})}$ & $73^{(\mathbf{5})}$ & - & $1,2^{(\mathbf{5})}$ & $3,4^{(5)}$ & $40^{(5)} \times 2$ & $40^{(5)} \times 2$ \\
\hline
\end{tabular}

${ }^{(1)}$ Sulfato de amônio. ${ }^{(2)}$ Cloreto de potássio. ${ }^{(3)}$ Sulfato de zinco. ${ }^{(4)}$ Uréia + Cloreto de potássio. ${ }^{(5)}$ NPK 20-00-20 + B e Zn. 
específicos ao controle de plantas daninhas e de insetos (praga) foram adotados, quando necessário, com o uso de herbicidas e inseticidas apropriados.

Observou-se a inconstância do regime pluviométrico no primeiro cultivo, com períodos de suprimento subótimo de água, notadamente no mês de janeiro, precedendo o florescimento do milho (Figura 1). De modo geral, as condições climáticas durante o segundo e o terceiro cultivo foram bem mais favoráveis à cultura, com maior volume de chuva e distribuição mais regular em relação ao cultivo inicial.

Por ocasião da colheita de cada cultivo, as plantas foram cortadas rente ao solo, tomando-se a massa da parte aérea (exceto espiga) e, posteriormente, dos grãos. Amostras dos grãos foram tomadas para determinação da concentração de $\mathrm{P}$, conforme método descrito por Malavolta et al. (1997). Tal análise também foi feita em amostras de folhas, colmo + pendão, palha e sabugo. Obtidos os teores de $\mathrm{P}$ e massas secas relativas às diferentes partes da planta, foram calculados os respectivos conteúdos de P.
Após a colheita da terceira safra, foi feita amostragem de solo na camada de $0-20 \mathrm{~cm}$, com pontos de coleta nas linhas e entrelinhas, totalizando dez amostras simples por parcela. O P foi determinado com o uso da resina de troca iônica (Raij \& Quaggio, 1983), de forma a quantificar o $P$ disponível residual referente a cada tratamento.

Os dados de produção e de acúmulo de $\mathrm{P}$ nas plantas de milho foram totalizados, calculando-se os resultados cumulativos obtidos após os três cultivos. Determinou-se a eficiência de utilização de P (EUP) pelo milho em cada tratamento, de acordo com a fórmula $\operatorname{EUP}\left(\mathrm{kg} \mathrm{kg}^{-1}\right)=$ produção de grãos $/ P$ acumulado na parte aérea (Moll et al., 1982).

As combinações de fontes e modos de aplicação de $\mathrm{P}$ foram comparadas em relação à sua eficiência relativa, tomando-se como, referencial (eficiência relativa $=100 \%$ ), a produção de grãos do tratamento que não recebeu adubação fosfatada (testemunha). Foi determinado o índice de eficiência agronômica das fontes para a produção de grãos, segundo Novais
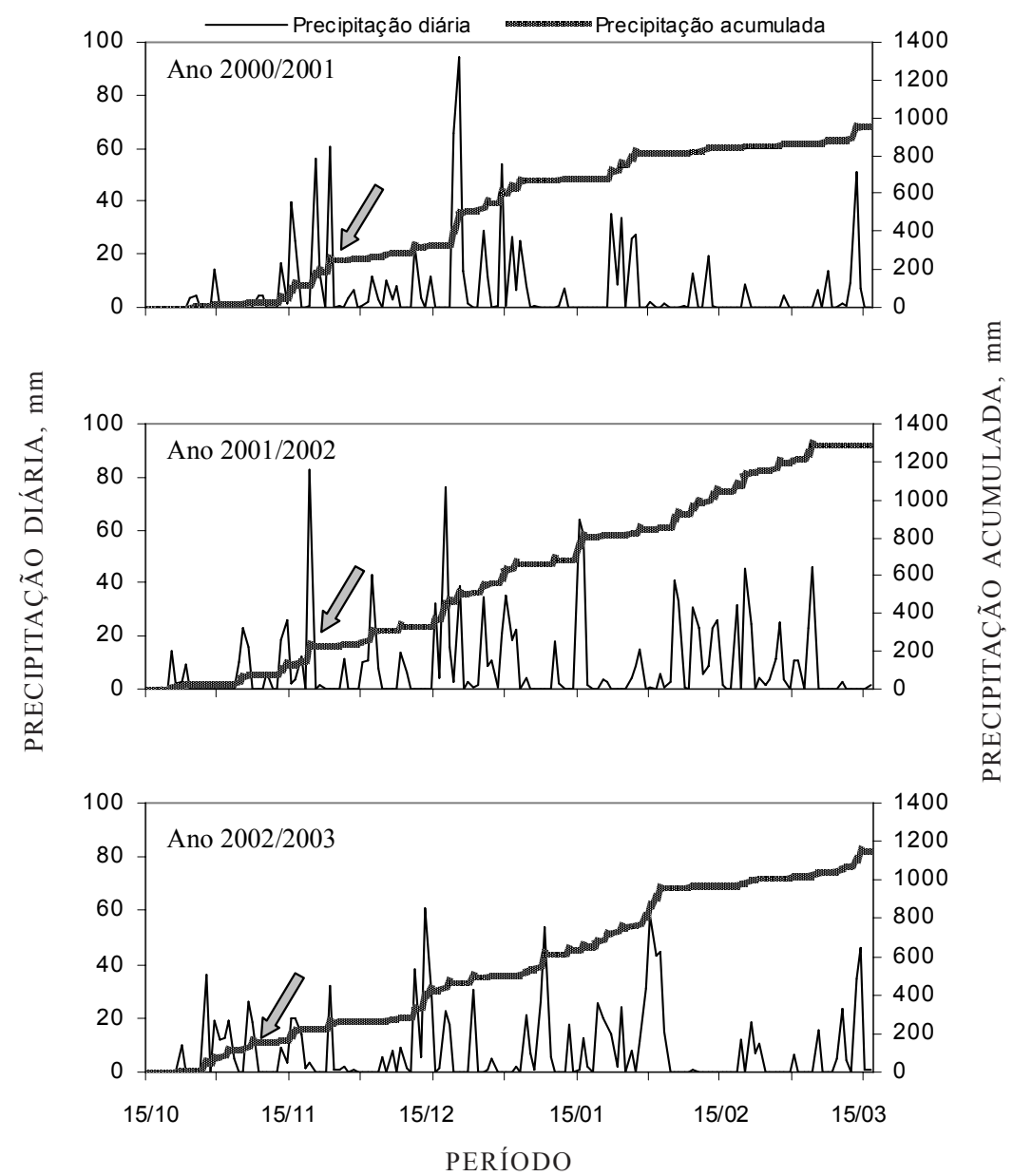

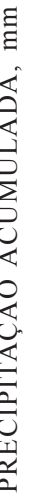

Figura 1. Dados pluviométricos referentes aos períodos dos três cultivos de milho (as setas indicam a época da semeadura). 
\& Smyth (1999). Considerou-se, em cada modo de aplicação, o superfosfato triplo como referência para aplicação da fórmula:

$\underset{\text { Egronômicia }(E A)}{\text { Efiencia }}=\frac{\text { Produção Fonte }- \text { Produção Testemunha }}{\text { Produção Super Triplo }- \text { Produção Testemunha }} \times 100$

Quando pertinente, os dados experimentais foram submetidos a análises de variância e testes de médias. Nas análises dos resultados acumulados após as três safras, as médias dos tratamentos componentes do fatorial foram comparadas entre si pelo teste de Tukey $(P \leq 0,05)$. Por meio do teste $\mathrm{F}$ $(P \leq 0,05)$, obteve-se a significância do contraste, comparando a média dos tratamentos do fatorial com a testemunha. Nas avaliações de resultados em anos isolados, o arranjo fatorial não pôde ser mantido, pois, no terceiro modo de aplicação, a dose de $180 \mathrm{~kg} \mathrm{ha}^{-1}$ de $\mathrm{P}_{2} \mathrm{O}_{5}$ só se completou ao final de três anos. Nesse caso, os 13 tratamentos foram comparados entre si (Teste de Scott-Knott), sem levar em conta a possibilidade de interação dos fatores fontes e modos de aplicação.

A avaliação econômica dos resultados, após três safras, foi realizada mediante ponderação da produtividade obtida nos diferentes tratamentos e do custo por unidade de $\mathrm{P}_{2} \mathrm{O}_{5}$ dos adubos fosfatados, tendo, como constantes, os gastos com os demais fatores de produção e desconsiderando eventuais diferenças de custo na aplicação dos fosfatos. Tal avaliação foi baseada nos preços de $\mathrm{R} \$ 2,13$; $\mathrm{R} \$ 3,04$; $\mathrm{R} \$ 1,62$; e $\mathrm{R} \$ 0,84$ por kg de $\mathrm{P}_{2} \mathrm{O}_{5}$ total posto em Lavras, $\mathrm{MG}$, o que correspondeu ao custo por tonelada de produto de $\mathrm{R} \$ 980,00 ; \mathrm{R} \$ 550,00 ; \mathrm{R} \$ 535,00$ e $\mathrm{R} \$ 190,00$; respectivamente, para as fontes ST, TM, FR e FA. A tomada de preços foi feita em fevereiro de 2004, e a equivalência em dólar foi obtida com base na cotação de $\mathrm{R} \$ 2,9303$ para o dólar americano. Calculou-se a relação benefício/custo referente aos tratamentos com fornecimento de $\mathrm{P}$, de acordo com os respectivos ganhos de produtividade proporcionados em relação ao tratamento-testemunha. Foi usado o preço de referência de $\mathrm{R} \$ 18,81$ a saca de milho de $60 \mathrm{~kg}$, de acordo com a cotação média do mês de janeiro de 2004.

Como os dados de produção acumulada de grãos foram semelhantes entre os tratamentos com as quatro fontes, foram estimados os pontos de equivalência de preço da tonelada de fertilizante (\% do custo do superfosfato triplo), os quais permitiriam obter, com o uso do termofosfato, fosfato reativo ou fosfato de Araxá, a mesma relação eficiência/custo do superfosfato triplo. Em outras palavras, esses pontos de equivalência indicariam, de acordo com a eficiência agronômica das fontes, o limite de custo da tonelada de adubo, abaixo do qual o uso do TM, FR e FA seria economicamente mais vantajoso em relação ao uso do ST (fonte de referência). Os pontos de equivalência foram obtidos, considerando o custo do TM, FR e FA como incógnitas em equações para igualar a relação eficiência/custo desses fertilizantes à eficiência/custo do ST.

\section{RESULTADOS E DISCUSSÃO}

\section{Produção de grãos}

Houve interação de fontes e modos de aplicação de $\mathrm{P}$ sobre a produção de grãos totalizada ao final dos três cultivos de milho. Não houve diferença entre fontes, considerando o modo de aplicação a lanço ou no sulco. Quando a adubação no sulco foi parcelada, o fosfato de Araxá (FA) proporcionou menor produção de grãos que o fosfato reativo (FR), mas ambas não diferiram do superfosfato triplo (ST) e do termofosfato (TM) (Quadro 4).

Quadro 4. Produção de grãos, considerando as fontes e modos de aplicação de fósforo na cultura do milho (total de três cultivos)

\begin{tabular}{lccc}
\hline \multirow{2}{*}{ Fonte de $\mathbf{P}$} & \multicolumn{2}{c}{ Modo de aplicação } \\
\cline { 2 - 4 } & Lanço & Sulco & Sulco parcelado \\
\cline { 4 - 4 } & & $\mathrm{kg} \mathrm{ha}^{-1}$ & $17.786 \mathrm{abA}$ \\
Superfosfato triplo & $17.998 \mathrm{aA}$ & $18.413 \mathrm{aA}$ & $17.609 \mathrm{abA}$ \\
Termofosfato & $18.065 \mathrm{aA}$ & $19.171 \mathrm{aA}$ & $19.433 \mathrm{aA}$ \\
F. Reativo & $16.476 \mathrm{aB}$ & $17.925 \mathrm{aAB}$ & $15.827 \mathrm{bA}$ \\
F. Araxá & $16.920 \mathrm{aA}$ & $17.189 \mathrm{aA}$ &
\end{tabular}

Médias seguidas de mesmas letras minúsculas, nas colunas, ou maiúsculas, nas linhas, não diferem entre si pelo teste de Tukey a $5 \%$.

**: Média do tratamento-testemunha difere em relação à média do fatorial (Teste $\mathrm{F}, p<0,01$ ). 
Somente para o FR, o rendimento de grãos dependeu de como o adubo foi distribuído. Melhores respostas foram obtidas, conforme a seqüência dos modos de aplicação: a lanço em área total $\leq$ localizada no sulco $\leq$ parcelada no sulco (Quadro 4). Na condição parcelada, o FR tendeu a superar as fontes mais solúveis ST e TM. A explicação provável desse resultado deve estar associada às características peculiares de solubilidade e à dinâmica de liberação de P do FR. Os fosfatos reativos caracterizam-se por apresentar solubilidade intermediária entre os fosfatos acidulados (ex: ST) e os fosfatos naturais brasileiros (ex: FA), o que lhes confere capacidade de liberação gradual do P no solo. Essa liberação ocorre por meio de processos semelhantes àqueles que controlam a solubilização dos fosfatos naturais brasileiros, porém de forma mais intensa (Rajan et al., 1996; Novais \& Smyth, 1999; Horowitz \& Meurer, 2003).

A aplicação e incorporação a lanço em área total não foi a melhor opção de manejo do FR, possivelmente pelo fato de o contato do adubo com maior volume de solo ocasionar a fixação do $\mathrm{P}$ liberado, antes que o nutriente pudesse ser absorvido pelo milho. Segundo Novais \& Smyth (1999), essa situação é típica nos solos tropicais mais intemperizados, nos quais os componentes do solo representam o dreno preferencial de $\mathrm{P}$ e a aplicação a lanço pode não ser adequada para atender à demanda da planta. A limitada velocidade de dissolução do FR, associada à dependência do processo de difusão para que ocorra o contato com a raiz, faz com que essa interação com o solo seja mais crítica, principalmente no caso do adubo disposto na entrelinha do milho, longe das raízes.

A distribuição do FR de forma localizada no sulco de semeadura e todo de uma só vez também não foi alternativa favorável à obtenção de maior produção de grãos. A dose utilizada $\left(180 \mathrm{~kg} \mathrm{ha}^{-1}\right.$ de $\left.\mathrm{P}_{2} \mathrm{O}_{5}\right)$, ocasionou provavelmente elevada concentração dos produtos da dissolução, $\mathrm{Ca}^{2+} \mathrm{e}_{2} \mathrm{PO}_{4}{ }^{-}$, saturando o ambiente de reação do fosfato e acabando por restringir a própria solubilização. A existência de componentes do solo, ou plantas, atuando como drenos de $\mathrm{P}$ e, principalmente, de Ca, é tida como fator preponderante para a dissolução e efetividade dos fosfatos naturais (Chien et al., 1980; Chien \& Menon, 1995; Rajan et al., 1996; Novais \& Smyth, 1999), mormente os reativos (Robinson et al., 1992). Nesse particular, é interessante notar que o milho não parece ser um dreno-Ca tão eficiente quanto outras culturas, como a soja (Raij \& Van Diest, 1979). Ao que tudo indica, a saturação do meio por cálcio impediu maior disponibilização de $\mathrm{P}$ do FR para o milho nesse tratamento, sobretudo no primeiro cultivo (Resende, 2004), quando o sistema solo-planta não representou um dreno-Ca suficientemente forte para estimular a dissolução do fosfato, situação agravada ainda mais pela disponibilização adicional de Ca oriundo da calagem.

Quando a aplicação do FR no sulco foi parcelada, obteve-se a melhor resposta em produção do milho.
Aparentemente, o fornecimento de apenas $60 \mathrm{~kg} \mathrm{ha}^{-1}$ de $\mathrm{P}_{2} \mathrm{O}_{5}$ a cada cultivo não comprometeu a solubilização do fosfato, enquanto o P liberado próximo à zona de crescimento das raízes do milho foi suficiente para atender à demanda da cultura nas condições de solo da área experimental. $\mathrm{O}$ mesmo não ocorreu com o uso do FA, evidenciando grande diferença entre os dois fosfatos nesse modo de aplicação.

Na realidade, a produção final proporcionada pelo FA foi semelhante nos três métodos de aplicação, indicativo de que a limitada solubilidade deve ter sido o principal fator condicionante da eficiência dessa fonte, independentemente do manejo da adubação. Em se tratando dos fosfatos naturais brasileiros, o revolvimento do solo constitui uma prática fundamental para o aumento da eficiência com o passar do tempo. Portanto, em sistemas de produção que não envolvem preparo do solo, não se deve esperar que a melhoria de desempenho do fosfato de Araxá seja similar à obtida com o preparo convencional (Lopes, 1999, Sousa \& Lobato, 2003).

Apesar dos presumíveis efeitos contrastantes dos tratamentos na disponibilização de $\mathrm{P}$ para a cultura, é nítida a tendência de nivelamento das respostas acumuladas após três safras de milho (Quadro 4), principalmente quando o nutriente foi aplicado todo de uma só vez no primeiro cultivo (modos de aplicação "lanço" e "sulco"). Essas considerações são concordantes com os padrões normalmente encontrados em estudos de longa duração. Confirmaram-se as premissas de que fontes mais solúveis proporcionam maior ganho inicial de produtividade, ao passo que o prolongado efeito residual das fontes de menor solubilidade pode, com o tempo, compensar a defasagem em relação às primeiras, notadamente no caso dos fosfatos reativos (Kaminski \& Peruzzo, 1997; Horowitz \& Meurer, 2003; Sousa \& Lobato, 2003).

É importante ressaltar que as condições de fertilidade do solo, antes da instalação do experimento, também devem ter contribuído, de forma expressiva, para o nivelamento dos efeitos de tratamentos. Prova disso é a considerável magnitude das produções observadas no tratamento-testemunha e nos tratamentos com aplicação de fosfatos naturais em apenas um terço da dose total a cada cultivo (Quadro 4). Certamente, tais resultados somente foram possíveis graças às reservas já existentes no solo. Apesar de os extratores Mehlich-1 e resina não terem sido sensíveis à presença dessas reservas (Quadro 1), esse argumento é bastante razoável, tendo em vista o fato de a área ter recebido adubações em épocas passadas.

Em solos com elevado fator capacidade de P (FCP), como no caso do presente trabalho (P-remanescente $=$ $16,8 \mathrm{mg} \mathrm{L}^{-1}$ ), o nível de fertilidade original pode ser determinante da eficiência dos fosfatos naturais, à semelhança do que ocorre para as fontes solúveis. Segundo Rajan et al. (1996), teoricamente, após a dissolução do fosfato natural (favorecida pela baixa concentração de P na solução do solo - elevado FCP), 
o P é fixado imediatamente, se a disponibilidade do nutriente estiver abaixo do nível crítico, mas permanece mais disponível, se o solo já tiver certa saturação do nutriente. Isso explicaria o desempenho relativamente satisfatório observado para os fosfatos naturais, mesmo o FA, nas condições do presente estudo.

Além disso, pode-se inferir que o grau de tamponamento do solo proporcionou disponibilidade de P compatível com a exigência do milho para os níveis de produtividade obtidos no tratamentotestemunha. Essa situação pode estar relacionada com a influência do capim-braquiária, resultando em maior biodisponibilidade de P (Goedert et al., 1986; Sousa et al., 2002; Sousa \& Lobato, 2003). O experimento foi instalado em área já adubada e que não era utilizada para lavouras há alguns anos, estando coberta por capim-braquiária, gramínea tida como bastante eficiente na absorção de $\mathrm{P}$, inclusive no aproveitamento de fontes pouco solúveis. Assim, apesar da baixa disponibilidade de $\mathrm{P}$ nas análises de rotina, poderia haver razoável estoque do nutriente nos restos vegetais da braquiária. Isso pode ter proporcionado uma condição peculiar em que o $\mathrm{P}$ convertido em formas orgânicas seria biodisponível (Sousa et al., 2002), condição a que os extratores Mehlich-1 e resina não seriam sensíveis. Nesse contexto, é plausível a hipótese de que tenha sido substancial a participação de formas orgânicas no suprimento total do nutriente para o milho, o que explicaria a produtividade observada no tratamentotestemunha.

\section{Absorção e eficiência de uso de fósforo}

Os dados de extração de $\mathrm{P}$, correspondentes à soma dos conteúdos de $\mathrm{P}$ da parte aérea, espigas e grãos, apresentaram estreita relação com a exportação do nutriente (Quadro 5). O grão foi o destino final da maior parte (87\%, em média) do $\mathrm{P}$ absorvido.

Embora as reservas de $\mathrm{P}$ do solo tenham representado parte expressiva do total do nutriente absorvido pelo milho, verifica-se que houve importante restrição do suprimento no tratamento-testemunha (Quadro 5). A amplitude relativamente pequena dos valores de $\mathrm{P}$ exportado, referentes aos tratamentos com fornecimento do nutriente (63,7 a 86,2 kg ha-1), está coerente com a semelhança das produtividades obtidas. No modo de aplicação parcelada, as fontes não diferiram entre si. De maneira geral, quando o $\mathrm{P}$ foi fornecido todo no primeiro ano ("lanço" e "sulco"), as fontes mais solúveis, ST e TM, favoreceram maior exportação do nutriente. Tendo em vista que as produtividades obtidas nesses dois modos de aplicação não diferiram entre os quatro fosfatos (Quadro 4), podese supor que houve consumo de luxo no caso das fontes de maior solubilidade.

Na média dos modos de aplicação, o uso das fontes ST, TM, FR e FA correspondeu, respectivamente, à recuperação de cerca de 49, 54, 46 e $33 \%$ do $\mathrm{P}$ fornecido. O melhor aproveitamento do $\mathrm{P}$ do termofosfato pode estar relacionado com a presença de $\mathrm{Mg}$ e de Si e com o poder neutralizante da acidez, característicos dessa fonte (Adams, 1980; Goedert et

Quadro 5. Extração de P pelo milho e exportação de fósforo nos grãos, considerando as fontes e modos de aplicação de fósforo (total de três cultivos)

\begin{tabular}{|c|c|c|c|}
\hline \multirow{2}{*}{ Fonte de $\mathbf{P}$} & \multicolumn{3}{|c|}{ Modo de aplicação } \\
\hline & Lanço & Sulco & Sulco parcelado \\
\hline & \multicolumn{3}{|c|}{ kg ha $\mathbf{a}^{-1}$} \\
\hline & \multicolumn{3}{|c|}{ Extração de $\mathrm{P}, \mathrm{kg} \mathrm{ha}^{-1}$} \\
\hline Superfosfato triplo & $90,3 \mathrm{aA}$ & $85,6 \mathrm{abA}$ & $91,7 \mathrm{abA}$ \\
\hline Termofosfato & $94,3 \mathrm{aA}$ & $99,1 \mathrm{aA}$ & $85,2 \mathrm{abA}$ \\
\hline F. Reativo & $85,8 \mathrm{abAB}$ & $76,5 \mathrm{bB}$ & $97,2 \mathrm{aA}$ \\
\hline F. Araxá & $73,9 \mathrm{bA}$ & $76,7 \mathrm{bA}$ & 77,6 bA \\
\hline \multirow[t]{2}{*}{ Testemunha } & $50,5^{* *}$ & & \\
\hline & \multicolumn{3}{|c|}{ Exportação de $\mathrm{P}, \mathrm{kg} \mathrm{ha}^{-1}$} \\
\hline Superfosfato triplo & 79,6 aA & $73,5 \mathrm{abA}$ & $79,3 \mathrm{aA}$ \\
\hline Termofosfato & $83,3 \mathrm{aA}$ & $86,2 \mathrm{aA}$ & 73,9 aA \\
\hline F. Reativo & $76,5 \mathrm{abAB}$ & $64,8 \mathrm{bA}$ & $81,5 \mathrm{aA}$ \\
\hline F. Araxá & $63,7 \mathrm{bA}$ & $65,0 \mathrm{bA}$ & 67,5 aA \\
\hline Testemunha & $44,4^{* *}$ & & \\
\hline
\end{tabular}


al., 1986; Tisdale et al., 1993, Malavolta, 2003). A recuperação de $\mathrm{P}$ do FA foi a menor dentre as fontes estudadas. Destaca-se, ainda, o melhor aproveitamento do FR (59 \%), quando aplicado parceladamente no sulco a cada cultivo.

A magnitude dos valores de recuperação obtidos não foi pequena, considerando o marcado caráterdreno de $\mathrm{P}$ dos solos da região do Cerrado. Sousa \& Lobato (2003) apresentaram dados de recuperação total de 35 a $62 \%$ do $\mathrm{P}$ aplicado, após 13 colheitas de milho em Latossolo argiloso de cerrado. A fonte utilizada foi o superfosfato simples, em doses variáveis, aplicadas a lanço de uma única vez ou parceladas no sulco. Os mesmos autores relataram que, num Latossolo muito argiloso adubado com superfosfato simples em doses de 100 a $800 \mathrm{~kg} \mathrm{ha}^{-1}$ de $\mathrm{P}_{2} \mathrm{O}_{5}$, a recuperação média de $\mathrm{P}$ após 17 anos foi de 36 e $61 \%$, respectivamente, quando a área foi plantada exclusivamente com culturas anuais e quando se intercalou Brachiaria humidicola por nove anos durante o período. Numa análise conjunta, esses resultados evidenciaram a influência da natureza do solo e da seqüência de culturas na eficiência de aproveitamento do $\mathrm{P}$ no sistema.

Reportando ao presente estudo, fundamenta-se, ainda mais, a hipótese de que o histórico da área tenha influenciado as respostas aos tratamentos, com provável participação de formas orgânicas (resultantes da presença do capim-braquiária) no suprimento de fósforo para o milho. Além disso, tomando como base os valores relativamente baixos de recuperação de $\mathrm{P}$ normalmente obtidos em solos de cerrado e considerando que foram feitos somente três cultivos após a aplicação dos tratamentos, deduzse que as taxas de recuperação do nutriente (30 a $62 \%$ ) no Argissolo estudado devem ter sido incrementadas em virtude da condição diferenciada de fertilidade da área à época da instalação do experimento, ou seja, do fato de a área já ter sido adubada anteriormente.
Os tratamentos que supriram menores quantidades de $\mathrm{P}$ levaram o milho a otimizar o uso do nutriente, resultando em maior quantidade de grãos produzidos por unidade de $\mathrm{P}$ absorvido (Quadro 6). As plantas de milho cultivadas no tratamentotestemunha apresentaram eficiência de utilização significativamente superior à média daquelas que receberam $\mathrm{P}$ na adubação. As diferenças entre tratamentos comprovam que, até certo ponto, os genótipos de milho utilizados no experimento foram capazes de compensar uma condição de menor disponibilidade de $\mathrm{P}$ com o aumento da conversão do nutriente em produto colhido. Assim, é plausível inferir que a plasticidade dos híbridos de milho, ligada à eficiência genotípica a fósforo, também contribuiu para o nivelamento das respostas obtidas em condições variáveis de suprimento do nutriente.

\section{Eficiência agronômica}

No quadro 7, são apresentados os resultados de eficiência relativa dos tratamentos, considerando a avaliação das produções isoladas ou total dos três cultivos. No primeiro ano, os incrementos em produtividade devido ao fornecimento de $\mathrm{P}$ foram inferiores aos obtidos nos anos seguintes. Atribuise esse resultado à forte limitação climática ocorrida em 2000/2001 (Figura 1), quando a escassez de chuvas e períodos de veranico restringiram seriamente o potencial de resposta do milho à adubação. É provável que tal limitação tenha prejudicado principalmente a resposta às fontes de maior solubilidade (ST e TM), das quais seria esperado melhor desempenho no ano da aplicação. Nos cultivos subseqüentes, a quantidade e a distribuição de chuvas foram mais favoráveis à cultura.

Observa-se que houve considerável aumento de eficiência relativa das fontes menos solúveis (FR e FA) com o passar do tempo, até o terceiro cultivo, o que não ocorreu no caso do ST (Quadro 7). Chama atenção a sensível melhoria da eficiência do tratamento em

Quadro 6. Eficiência de utilização de fósforo, considerando as fontes e modos de aplicação de fósforo na cultura do milho (total de três cultivos)

\begin{tabular}{|c|c|c|c|}
\hline \multirow{2}{*}{ Fonte de $\mathbf{P}$} & \multicolumn{3}{|c|}{ Modo de aplicação } \\
\hline & Lanço & Sulco & Sulco parcelado \\
\hline & \multicolumn{3}{|c|}{$\mathrm{kg} \mathrm{kg}^{-1}$} \\
\hline Super triplo & $203 \mathrm{abA}$ & $216 \mathrm{abA}$ & $196 \mathrm{aA}$ \\
\hline Termofosfato & $192 \mathrm{bA}$ & $195 \mathrm{bA}$ & $208 \mathrm{aA}$ \\
\hline F. Reativo & $193 \mathrm{bB}$ & $236 \mathrm{aA}$ & $201 \mathrm{aB}$ \\
\hline F. Araxá & $230 \mathrm{aA}$ & 225 aA & 205 aA \\
\hline Testemunha & $249 * *$ & & \\
\hline
\end{tabular}

Eficiência de utilização = Produção de grãos/P acumulado na parte aérea.

Médias seguidas de mesmas letras minúsculas, nas colunas, ou maiúsculas, nas linhas, não diferem entre si pelo teste de Tukey a $5 \%$.

**: Média do tratamento-testemunha difere (>) em relação à média do fatorial (Teste $\mathrm{F}, p<0,01$ ). 
Quadro 7. Eficiência relativa de produção de grãos, considerando as fontes e modos de aplicação de fósforo na cultura do milho, em três cultivos

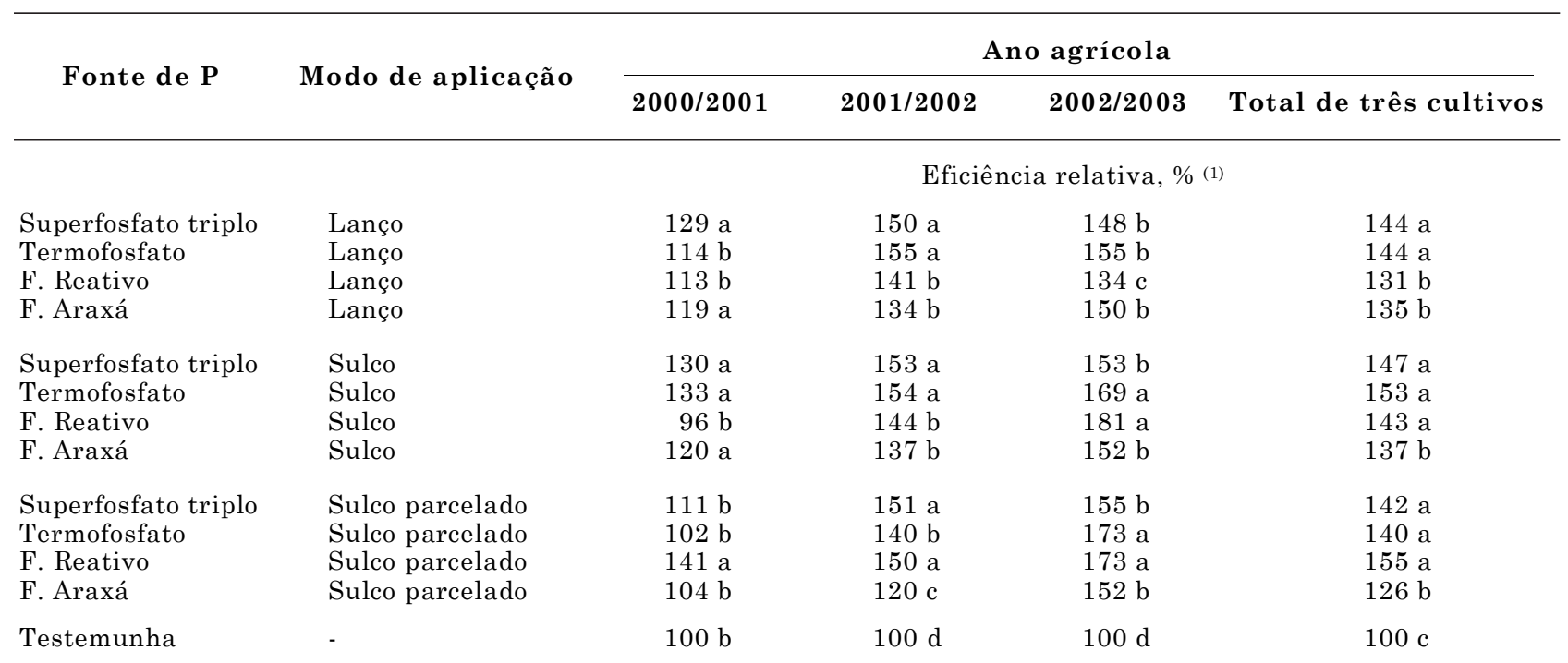

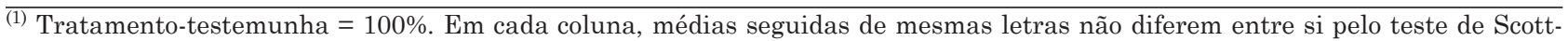
Knott a $5 \%$.

que a dose total do FR foi aplicada no sulco no primeiro ano. Nesse caso, a explicação parece estar relacionada com as condições que interferem na dissolução dos fosfatos reativos, especificamente a elevada saturação por Ca no ambiente de reação do produto, impedindo maior liberação inicial de P (Chien et al., 1980; Chien \& Menon, 1995; Rajan et al., 1996; Korndörfer et al., 1999; Novais \& Smyth, 1999).

Em geral, em cada cultivo, as diferenças entre os tratamentos não foram tão intensas quanto normalmente seria esperado, havendo certa tendência de equiparação da eficiência, o que refletiu na produção acumulada dos três cultivos (Quadro 7). Fatores ligados ao histórico da área (adubações e presença do capim-braquiária em épocas passadas), ao tamponamento do solo (atuando como fonte de $\mathrm{P}$, nos tratamentos mais restritivos, e como dreno, nos tratamentos com maior disponibilização do nutriente) e à eficiência dos híbridos de milho (elevada eficiência de uso de P) parecem estar envolvidos, de forma aditiva, na equiparação dos resultados de longo prazo (Quadros 4 e 7).

Em virtude do exposto, apesar de expressivos, os incrementos de produtividade nos tratamentos com fornecimento de $\mathrm{P}$ não são da mesma magnitude daqueles verificados nos experimentos de adubação fosfatada em solos virgens de cerrado, nos quais, via de regra, a produção do tratamento-testemunha é extremamente baixa (Sousa \& Lobato, 2003). Entretanto, a obtenção de eficiência similar para tratamentos contrastantes é uma perspectiva concreta nas áreas de cerrado submetidas ao cultivo e adubadas há mais tempo, situações em que o solo adquire caráter-fonte de fósforo mais pronunciado ou reduz o caráter-dreno. Dynia \& Camargo (1997) verificaram que, após 17 cultivos (arroz, feijão, trigo e milho) durante seis anos e meio com adubações de manutenção, houve redução da capacidade de adsorção de $\mathrm{P}$ de um Latossolo argiloso de cerrado, significando a possibilidade de diminuição da dose de fertilizante fosfatado nas adubações futuras.

Os índices de eficiência agronômica, calculados com referência ao superfosfato triplo, evidenciam que o FA e o FR são realmente produtos muito distintos quanto ao potencial de suprimento de P (Quadro 8). Em termos absolutos, na aplicação a lanço, os dois fosfatos tiveram comportamento bastante similar. $\mathrm{Na}$ aplicação localizada no sulco, o FR despontou como fonte mais promissora. O parcelamento da aplicação no sulco incrementou significativamente a resposta do milho ao FR, mas não contribuiu para maior eficiência do FA. Já as fontes mais solúveis, ST e TM, apresentaram eficiência semelhante, sendo menos afetadas pelo modo de aplicação.

\section{Eficiência econômica}

Analisando a relação benefício/custo dos tratamentos (Quadro 9), depreende-se que, embora associado à obtenção de boas produtividades, o termofosfato foi a fonte de menor vantagem econômica, decorrente do custo proporcionalmente mais elevado em relação às demais. $\mathrm{O}$ alto custo parece realmente ser a principal limitação do uso do termofosfato, haja vista que, agronomicamente, o produto costuma superar, em eficiência, os superfosfatos (Goedert \& Lopes, 1987).

Apesar de apresentarem menor efetividade em termos agronômicos (Quadros 7 e 8), as fontes menos 
solúveis, FR e FA, foram economicamente mais viáveis. Dependendo do modo de aplicação, o uso do fosfato de Araxá resultou em relação benefício/custo duas vezes mais compensadora que a obtida com o superfosfato triplo (Quadro 9). Essa situação devese a uma conjunção de fatores. Pelo próprio fato de avaliar-se a produção acumulada de vários cultivos, normalmente, há alguma redução nas diferenças entre tratamentos com adubação fosfatada (Goedert \& Lobato, 1984; Sousa \& Lobato, 2003). Além disso, as condições de solo (existência de reserva de $\mathrm{P}$ em decorrência de adubações passadas) e da planta (eficiência genotípica a P) parecem ter favorecido as respostas do milho nos tratamentos com menor disponibilização de $\mathrm{P}$, fazendo com que as discrepâncias de produtividade não fossem tão acentuadas. Um terceiro aspecto a ser considerado é que, nos últimos tempos, a utilização agrícola do fosfato de Araxá decresceu substancialmente e o menor preço do produto, em comparação às outras fontes, pode, em parte, ser reflexo da baixa demanda.

Dada a semelhança dos tratamentos quanto à eficiência agronômica, as informações oriundas de uma avaliação econômica criteriosa adquirem importância ainda maior, como subsídio para tomada de decisão na escolha da fonte e do método de aplicação de $\mathrm{P}$. Os dados do quadro 10 permitem conhecer, para o termofosfato, fosfato reativo e fosfato de Araxá, qual o custo proporcional da tonelada desses produtos, em relação ao superfosfato triplo, que possibilitaria obter o mesmo fator eficiência/custo do superfosfato. Em outras palavras, os valores apresentados são estimativas de qual deveria ser o preço dos fosfatos para igualar a relação eficiêncial custo de todos eles, tomando, como referência, os dados relativos ao superfosfato triplo e considerando a dose padronizada de $180 \mathrm{~kg} \mathrm{ha}^{-1}$ de $\mathrm{P}_{2} \mathrm{O}_{5}$. Embora se restrinjam ao caso do presente experimento, tais estimativas constituem uma forma de comparação interessante para outras áreas com características de resposta à adubação semelhantes às encontradas neste estudo (respostas similares para diferentes estratégias de manejo da adubação).

Verifica-se que, na média das três formas de aplicação, o custo do TM deveria corresponder a, no máximo, $41,4 \%$ do preço do ST para viabilizar sua utilização nas condições do experimento. De acordo com a cotação dos produtos, a proporção atual é de $56,1 \%$ (Quadro 10). Inversamente, nas mesmas circunstâncias, o FA poderia custar até $36,1 \%$, mas o custo atual é de 19,4\% em relação ao ST. Interessante notar que o FR foi mais influenciado pelo modo de aplicação, e maiores vantagens, ponderando custo e eficiência agronômica, foram obtidas, conforme

Quadro 8. Eficiência agronômica de fontes e modos de aplicação de fósforo na cultura do milho (total de três cultivos)

\begin{tabular}{|c|c|c|c|}
\hline \multirow{2}{*}{ Fonte de $\mathbf{P}$} & \multicolumn{3}{|c|}{ Modo de aplicação } \\
\hline & Lanço & Sulco & Sulco parcelado \\
\hline & \multicolumn{3}{|c|}{ Eficiência agronômica, \% (1) } \\
\hline Superfosfato triplo & $100 \mathrm{aA}$ & $100 \mathrm{aA}$ & $100 \mathrm{abA}$ \\
\hline Termofosfato & $104 \mathrm{aA}$ & $114 \mathrm{aA}$ & $98 \mathrm{abA}$ \\
\hline F. Reativo & $74 \mathrm{aB}$ & $94 \mathrm{aB}$ & $133 \mathrm{aA}$ \\
\hline F. Araxá & $79 \mathrm{aA}$ & $79 \mathrm{aA}$ & $62 \mathrm{bA}$ \\
\hline
\end{tabular}

(1) Tratamento com superfosfato triplo como referência (em cada modo de aplicação, eficiência $=100 \%$ ).

Médias seguidas de mesmas letras minúsculas, nas colunas, ou maiúsculas, nas linhas, não diferem entre si pelo teste de Tukey a $5 \%$.

Quadro 9. Relação benefício/custo, considerando as fontes e modos de aplicação de fósforo na cultura do milho (total de três cultivos)

\begin{tabular}{lcccc}
\hline \multirow{2}{*}{ Fonte de P } & \multicolumn{3}{c}{ Modo de aplicação } & Média \\
\cline { 2 - 4 } & Lanço & Sulco & Sulco parcelado & \\
\hline Superfosfato triplo & 4,5 & 4,8 & 4,3 & 4,5 \\
Termofosfato & 3,2 & 3,8 & 2,9 & 3,3 \\
F. Reativo & 4,2 & 5,8 & 7,4 & 5,8 \\
F. Araxá & 9,1 & 9,7 & 6,9 & 8,6 \\
Média & 5,3 & 6,0 & 5,4 & 5,6 \\
\hline
\end{tabular}


a seqüência: aplicação a lanço < aplicação no sulco < aplicação no sulco parcelada.

O fosfato de Araxá e o fosfato reativo seriam as melhores alternativas na escolha de fontes de P para o milho, apresentando melhor compatibilização do custo do fertilizante e da resposta em produção de grãos para o investimento em $180 \mathrm{~kg} \mathrm{ha}^{-1}$ de $\mathrm{P}_{2} \mathrm{O}_{5}$. Todavia, essas alternativas não estão vinculadas à obtenção de produtividades iguais às proporcionadas pelo superfosfato triplo, mas iguais àquelas observadas nos respectivos tratamentos. Portanto, os valores percentuais do quadro servem como indicadores do custo, abaixo do qual haveria lucro com determinado tratamento, comparativamente ao uso da fonte-padrão (ST). No caso em questão, ficou claro que os tratamentos mais convenientes quanto ao aspecto econômico não necessariamente correspondem àqueles agronomicamente mais promissores.

\section{Efeito residual}

Excetuando o FA, a estratégia de fornecimento do $\mathrm{P}$ de forma parcelada foi mais efetiva em manter o efeito residual das fontes (Quadro 11), provavelmente em virtude da condição diferencial de absorção e de exposição dos fosfatos à interação com o solo (menor tempo de contato). O parcelamento preveniu, tanto o consumo de luxo pelo milho, quanto o processo de fixação, considerando o tempo de permanência dos fosfatos em contato com o solo.

O maior efeito residual, associado a uma boa produção de grãos, foi propiciado pelo FR parcelado e deve ser resultante de uma velocidade intermediária de liberação de $\mathrm{P}$, que não comprometeu a absorção pelo milho, mas que, aparentemente, minimizou os processos de fixação do nutriente em comparação às fontes de maior solubilidade. Considerando que adsorção e difusão são processos que concorrem na depleção do P-solução oriundo do fertilizante, o resultado obtido com o FR é coerente com a afirmação de Novais \& Smyth (1999) de que, em solo-dreno, pode ser mais conveniente o uso de fontes menos solúveis, desde que a menor solubilidade não implique restrição do processo de difusão, o qual garante o suprimento de $\mathrm{P}$ à planta. No caso, o FA parece não atender a esse requisito. De acordo com Rajan et al. (1996), os fosfatos naturais de boa qualidade são as fontes ideais para o manejo de longo prazo, pois acabam sendo uma fonte de liberação controlada de P.

Quadro 10. Ponto de equivalência de preço da tonelada de fertilizante, o qual permitiria a mesma relação eficiência/custo do superfosfato triplo

\begin{tabular}{|c|c|c|c|c|c|}
\hline \multirow{2}{*}{ Fonte de $\mathrm{P}$} & \multicolumn{3}{|c|}{ Modo de aplicação } & \multirow{2}{*}{ Média } & \multirow{2}{*}{$\%$ atual $^{(1)}$} \\
\hline & Lanço & Sulco & Sulco parcelado & & \\
\hline & \multicolumn{5}{|c|}{$\%$ do custo do superfosfato triplo } \\
\hline Termofosfato & 40,8 & 44,8 & 38,5 & 41,4 & 56,1 \\
\hline F. Reativo & 53,1 & 67,5 & 95,5 & 72,0 & 54,6 \\
\hline F. Araxá & 38,9 & 38,9 & 30,5 & 36,1 & 19,4 \\
\hline
\end{tabular}

(1) Relação de custos atual, de acordo com as cotações dos fertilizantes, por ocasião da tomada de preços.

Quadro 11. Fósforo disponível residual, após três cultivos de milho, considerando as fontes e modos de aplicação de fósforo

\begin{tabular}{lccc}
\hline \multirow{2}{*}{ Fonte de $\mathbf{P}$} & \multicolumn{2}{c}{ Modo de aplicação } \\
\cline { 2 - 3 } & Lanço & Sulco & Sulco parcelado \\
\cline { 2 - 3 } & & $\mathrm{mg} \mathrm{dm}^{-3}$ & $17,1 \mathrm{bA}$ \\
Superfosfato triplo & $10,0 \mathrm{aB}$ & $10,2 \mathrm{aB}$ & $16,3 \mathrm{bcA}$ \\
Termofosfato & $9,7 \mathrm{aB}$ & $10,5 \mathrm{aB}$ & $24,9 \mathrm{aA}$ \\
F. Reativo & $12,1 \mathrm{aB}$ & $13,2 \mathrm{aB}$ & $12,0 \mathrm{cA}$ \\
F. Araxá & $9,8 \mathrm{aA}$ & $11,1 \mathrm{aA}$ & \\
Testemunha & $8,7^{* *}$ & & \\
\hline
\end{tabular}

P extraído com resina de troca iônica.

Médias seguidas de mesmas letras minúsculas, nas colunas, ou maiúsculas, nas linhas, não diferem entre si pelo teste de Tukey a $5 \%$.

**: Média do tratamento-testemunha difere em relação à média do fatorial (Teste $\mathrm{F}, p<0,01$ ). 
Nas condições de solo, clima e manejo geral da área e para os tetos de produtividade alcançados no experimento (em torno de $8 \mathrm{t} \mathrm{ha}^{-1}$ de grãos, numa safra), parece clara a conveniência de se adotar a estratégia de adubação parcelada, como forma de otimizar o manejo da fertilidade do solo, aliando aspectos técnicos e econômicos do fornecimento de $\mathrm{P}$ para o milho. Tudo leva a crer que os $60 \mathrm{~kg} \mathrm{ha}^{-1} \mathrm{de}$ $\mathrm{P}_{2} \mathrm{O}_{5}$, aplicados anualmente, foram suficientes para propiciar ganhos de produtividade, repor o $\mathrm{P}$ exportado e, ainda, incrementar o $\mathrm{P}$ disponível no solo, com um excedente capaz de melhorar a fertilidade para os cultivos seguintes.

\section{CONCLUSÕES}

1. As diferenças entre tratamentos foram detectadas em termos de quantidade de $\mathrm{P}$ absorvido, mas não tiveram correspondente efeito sobre a produtividade do milho. De modo geral, o uso de fontes com solubilidade variável e em distintos modos de aplicação proporcionou incrementos semelhantes na produção acumulada dos três cultivos.

2. As fontes mais solúveis, superfosfato triplo e termofosfato, apresentaram desempenho similar para a maioria das variáveis analisadas. Somente para o fosfato reativo de Arad, a produtividade de grãos dependeu de como o adubo foi distribuído. Melhores respostas foram obtidas, conforme a seqüência dos modos de aplicação: a lanço em área total < localizada no sulco < parcelada no sulco. Quando usado de forma parcelada, o fosfato reativo tendeu a proporcionar produtividade superior à do superfosfato triplo e do termofosfato. O fosfato de Araxá apresentou menor capacidade de suprimento de $\mathrm{P}$ para o milho, não havendo vantagem para nenhum dos métodos de aplicação testados.

3. As fontes diferiram entre si, quanto à eficiência agronômica, apenas quando aplicadas de forma parcelada. O fosfato reativo de Arad e o fosfato de Araxá apresentaram, respectivamente, a maior e a menor eficiência nesse modo de aplicação. $\mathrm{O}$ fosfato reativo foi a única fonte cuja eficiência agronômica dependeu do modo de aplicação, sendo maior quando o adubo foi aplicado no sulco e parcelado anualmente.

4. Os tratamentos com maior eficiência agronômica não corresponderam aos de maior eficiência econômica. O termofosfato foi tecnicamente promissor, mas, em retorno econômico, foi superado pelas demais fontes. Os dois fosfatos naturais apresentaram relação benefício/custo mais compensadora.

5. A aplicação localizada no sulco e o parcelamento da adubação proporcionaram maior eficiência agronômica e econômica para o fosfato reativo, o que não ocorreu no caso do fosfato de Araxá.
6. O parcelamento da dose total dos fosfatos em aplicações anuais no sulco de semeadura não comprometeu a produtividade do milho e propiciou maior efeito residual, notadamente no caso do fosfato reativo.

\section{AGRADECIMENTOS}

Às empresas, Serrana Fertilizantes S.A., Fertilizantes Ouro Verde S.A. e Fertilizantes Mitsui S.A., pela parceria, fornecendo parte dos fertilizantes usados no estudo.

\section{LITERATURA CITADA}

ADAMS, F. Interactions of phosphorus with other elements in soil and in plants. In: KHASAWNEH, F.E.; SAMPLE, E.C. \& KAMPRATH, E.J., eds. The role of phosphorus in agriculture. Madison, American Society of Agronomy, 1980. p.655-680.

ALVAREZ V., V.H.; NOVAIS, R.F.; BARROS, N.F.; CANTARUTTI, R.B. \& LOPES, A.S. Interpretação dos resultados das análises de solos. In: RIBEIRO, A.C.; GUIMARÃES, P.T.G. \& ALVAREZ V., V.H., eds. Recomendações para o uso de corretivos e fertilizantes em Minas Gerais: 5a aproximação. Viçosa, MG, Comissão de Fertilidade do Solo do Estado de Minas Gerais, 1999. p.25-32.

ALVES, V.M.C.; VASCONCELLOS, C.A.; FREIRE, F.M.; PITTA, G.V.E.; FRANÇA, G.E.; RODRIGUES FILHO, A.; ARAÚJO, J.M.; VIEIRA, J.R. \& LOUREIRO, J.E. Milho. In: RIBEIRO, A.C.; GUIMARÃES, P.T.G. \& ALVAREZ V., V.H., eds. Recomendações para o uso de corretivos e fertilizantes em Minas Gerais: 5a aproximação. Viçosa, MG,Comissão de Fertilidade do Solo do Estado de Minas Gerais, 1999. p.314-316.

BARBOSA FILHO, M.P. Utilização de fosfatos naturais em solos de cerrado. Piracicaba, Potafos, 1984. p.1-4. (Informações Agronômicas, 28)

CHIEN, S.H. \& MENON, R.G. Factors affecting the agronomic effectiveness of phosphate rock for direct application. Fertil. Res., 41:227-234, 1995.

CHIEN, S.H.; LÉON, L.A. \& TEJADA, H.R. Dissolution of phosphate rocks in acid Colombian soils as related to soil properties. Soil Sci. Soc. Am. J., 44:1267-1271, 1980.

COELHO, A.M. \& ALVES, V.M.C. Adubação fosfatada na cultura do milho. In: SIMPÓSIO SOBRE FÓSFORO NA AGRICULTURA BRASILEIRA, Piracicaba, 2003. Anais. Piracicaba, Potafos/Anda, 2003. 31p. CD-ROM

DYNIA, J.F. \& CAMARGO, O.A. Efeitos da adubação fosfatada e da calagem sobre a adsorção de fósforo em um Latossolo Vermelho-Escuro. Pesq. Agropec. Bras., 32:865-868, 1997. 
EMPRESA BRASILEIRA DE PESQUISA AGROPECUÁRIA EMBRAPA. Embrapa Solos, Embrapa Informática Agropecuária. Manual de análises químicas de solos, plantas e fertilizantes. Brasília, Embrapa Comunicação para Transferência de Tecnologia, 1999. 370p.

FIXEN, P.E. \& HALVORSON, A.D. Optimum phosphorus management for small grain production. Better Crops With Plant Food, 75:26-29, 1991.

GOEDERT, W.J. \& LOBATO, E. Eficiência agronômica de fosfatos em solo de cerrado. R. Bras. Ci. Solo, 8:97-102, 1984.

GOEDERT, W.J. \& LOPES, A.S. Eficiência agronômica de fertilizantes fosfatados para culturas anuais, perenes, pastagens e reflorestamento. In: SEMINÁRIO SOBRE RECUPERAÇÃO DE FÓSFORO, São Paulo, 1987. Anais. São Paulo, Ibrafos, 1987. p.24-49.

GOEDERT, W.J.; SOUSA, D.M.G. \& LOBATO, E. Fósforo. In: GOEDERT, W.J., ed. Solos dos cerrados: tecnologias e estratégias de manejo. São Paulo, Nobel, 1986. p.129. 166 .

HOROWITZ, N. \& MEURER, E.J. Eficiência agronômica de fosfatos naturais. In: SIMPÓSIO SOBRE FÓSFORO NA AGRICULTURA BRASILEIRA, Piracicaba, 2003. Anais. Piracicaba, Potafos/Anda, 2003. 24p. CD-ROM

KAMINSKI, J. \& PERUZZO, G. Eficácia de fosfatos naturais reativos em sistemas de cultivo. Santa Maria, Sociedade Brasileira de Ciência do Solo, 1997. 31p. (Boletim Técnico, 3)

KORNDÖRFER, G.H.; LARA-CABEZAS, W.A. \& HOROWITZ, N. Eficiência agronômica de fosfatos naturais reativos na cultura do milho. Sci. Agric., 56:391-396, 1999.

LOPES, A.S. Fosfatos naturais. In: RIBEIRO, A.C.; GUIMARÃES, P.T.G. \& ALVAREZ V., V.H., eds. Recomendações para o uso de corretivos e fertilizantes em Minas Gerais: 5a aproximação. Viçosa, MG, Comissão de Fertilidade do Solo do Estado de Minas Gerais, 1999. p.65-66.

MALAVOLTA, E. Fósforo na planta e interação com outros elementos. In: SIMPÓSIO SOBRE FÓSFORO NA AGRICULTURA BRASILEIRA, Piracicaba, 2003. Anais. Piracicaba, Potafos/Anda, 2003. 85p. CD-ROM

MALAVOLTA, E.; VITTI, G.C. \& OLIVEIRA, S.A. Avaliação do estado nutricional das plantas: Princípios e aplicações. 2.ed. Piracicaba, Potafos, 1997. 319p.

MOLL, R.H.; KAMPRATH, E.J. \& JACKSON, W.A. Analysis and interpretation of factors which contribute to efficiency of nitrogen utilization. Agron. J., 74:562-564, 1982.
NOVAIS, R.F. \& SMYTH, T.J. Fósforo em solo e planta em condições tropicais. Viçosa, MG, Universidade Federal de Viçosa, 1999. 399p.

PROCHNOW, L.I.; ALCARDE, J.C. \& CHIEN, S.H. Eficiência agronômica dos fosfatos totalmente acidulados. In: SIMPÓSIO SOBRE FÓSFORO NA AGRICULTURA BRASILEIRA, Piracicaba, 2003. Anais. Piracicaba, Potafos/Anda, 2003. 67p. CD-ROM

RAIJ, B. van \& QUAGGIO, J.A. Métodos de análise de solos para fins de fertilidade. Campinas, Instituto Agronômico, 1983. 31p. (Boletim, 81)

RAIJ, B. van \& VAN DIEST, A. Utilization of phosphate from different sources by six plant species. Plant Soil, 51:577589,1979

RAIJ, B. van. Fertilidade do solo e adubação. Piracicaba, Potafos, 1991. 343p.

RAIJ, B. van; QUAGGIO, J.A.; CANTARELLA, H. \& ABREU, C.A. Interpretação de resultados de análise de solo. In: RAIJ, B. van; CANTARELLA, H.; QUAGGIO, J.A. \& FURLANI, A.M.C., eds. Recomendações de adubação e calagem para o Estado de São Paulo. Campinas, Instituto Agronômico, 1996. p.8-13.

RAJAN, S.S.S.; WATKINSON, J.H. \& SINCLAIR, A.G. Phosphate rocks for direct application to soils. Adv. Agron., 57:77-159, 1996

REETZ JUNIOR, H.F. \& FIXEN, P.E. Economics of long-term vs short-term soil fertility management. Better Crops With Plant Food, 76:8-11, 1992.

RESENDE, A.V. Fontes e modos de aplicação de fósforo para o milho em solo cultivado da região do Cerrado. Lavras, Universidade Federal de Lavras, 2004. 169p. (Tese de Doutorado)

ROBINSON, J.S.; SYERS, J.K. \& BOLAN, N.S. Importance of proton supply and calcium-sink size in the dissolution of phosphate rock materials of different reactivity in soil. J. Soil Sci., 43:447-459, 1992.

SOUSA, D.M.G. \& LOBATO, E. Adubação fosfatada em solos da região do Cerrado. Piracicaba, Potafos, 2003. 16p. (Informações Agronômicas, 102)

SOUSA, D.M.G.; LOBATO, E. \& REIN, T.A. Adubação com fósforo. In: SOUSA, D.M.G. \& LOBATO, E., eds. Cerrado: correção do solo e adubação. Planaltina, Embrapa Cerrados, 2002. p.147-168.

TISDALE, S.L.; NELSON, W.L.; BEATON, J.D. \& HAVLIN, J.L. Soil fertility and fertilizers. 5.ed. Nova York, Macmillan Publishing Company, 1993. 634p. 